\title{
Teatro de sombras en educación infantil: unproyecto para el festival de Navidad Shade Theatre and Learning Project Methodology. An experience of Physical Education Infant Education
}

\author{
María Isabel Martín* y Víctor López Pastor** \\ *C.R.A. «Campos Castellanos» - Segovia, **E. U. Magistrerio de Segovia
}

\begin{abstract}
Resumen: En este artículo presentamos una experiencia didáctica centrada en el desarrollo de un proyecto de aprendizaje en torno al teatro de sombras con el alumnado de educación infantil. El proyecto giraba en torno a la preparación de la actuación de los grupos de educación infantil en el festival de navidad que se hace el último día de clase, delante de las familias y el resto de compañeros. La maestra de psicomotricidad decidió probar con un recurso nuevo este año: la dramatización de cuentos infantiles a través del teatro de sombras. En este trabajo presentamos las razones por las que surge el proyecto, como lo llevamos a cabo y una valoración final sobre su desarrollo y el proceso seguido. El objetivo era iniciar al alumnado de Educación Infantil en la dramatización a través del teatro de sombras. Para ello se prepararon tres representaciones durante las semanas anteriores, una para cada curso. Los materiales utilizados son sencillos: un telón blanco, un foco de luz y algunos objetos para ajustar la sombras a los detalles de los cuentos. Hemos comprobado que el alumnado de infantil es capaz de asimilar las técnicas básicas del teatro de sombras y desarrollar representaciones de buena calidad.. Palabras clave: Teatro de sombras, Educación Física, Educación Infantil, Dramatización.
\end{abstract}

Abstract: In this article we present a didactic experience centered in a learning project with shade theatre carried out with the pupil of Infant Education. The project developed around the preparation of the performance by Infant Education groups at the Christmas festival. The festival takes part in the last school day in front of the families and the rest of children. The P.E. teacher decided to try out a new resource this year: the dramatization of children stories through shade theatre. In this work we present the reasons why the project arises, the way it was carried out, and a final assessment on its development and the whole process. The objective was to initiate Infant Education children in drama through the shade theatre. In order to do this three performances were shown during the previous weeks, one for each age level. The materials used are simple: a white curtain, a spot-light and some objects to adjust the shades to the characteristics of the stories. We have confirmed that the Infant School children are able to assimilate the basic techniques of the shade theatre and to carried out good quality performances.

Key words: Shade Theatre, Physical Education, Infant Education, Dramatization.

\section{Introducción. Contexto en que se lleva a cabo la experien-} cia.

Esta experiencia se lleva a cabo en la escuela rural, en el colegio cabecera de un Centro Rural Agrupado(CRA) dela provincia de Segovia. ElCRA está compuesto por 3 pueblos. La cabecera es un colegio de una línea con un aula por año, incluido $1^{\circ}$ y $2^{\circ}$ de ESO. El siguiente pueblo más grande tiene cinco grupos (dos de Infantil y tres de Primaria). El pueblo más pequeño tiene una escuela incompleta de dos unidades (una para Infantil y otra para Primaria).

Actualmente, el CRA tiene 258 alumnos, aunque dicho número varia con frecuencia, por la llegando de nuevo alumnado inmigrante a lo largo del curso. El claustro del centro está formado por 28 profesores.

La profesora que llevó a cabo el proyecto tiene doble especialidad (educación infantil y educación física) y estaba ocupando la plaza de profesora de apoyo y psicomotricidad en educación infantil, por lo que itineraba por las escuelas de las diferentes localidades, desarrollando las sesiones de «psicomotricidad» y una serie de «apoyos». Eso era lo previsto, pero a menudo tocaba hacer sustituciones, cubrir bajas, ausencias... Estas características de la realidad escolar dificultan considerablemente la posibilidad de desarrollar el programa de motricidad con la continuidad que sería deseable.

La unidad didáctica «Conocemos el mundo de las sombras corporales» formaba parte de su programación de Psicomotricidad para Educación Infantil del curso 2005-2006 y se llevaba a cabo a través de la metodología de proyectos de aprendizaje. Previamente habíamos desarrollado proyectos similares en Primaria, que habían funcionado muy bien. Esta vez el reto era nuevo; había que llevarlo a cabo en Infantil, y la diferencia de edad y capacidades nos genera ciertas dudas sobre su viabilidad.

\footnotetext{
Fecha de recepción: 19-01-07 - Fecha de aceptación: 30-07-07

Correspondencia: Víctor López Pastor

Plaza Colmeranes, 1

40001 Segovia

E-mail: vlopez@mpc.uva.es
}

\section{Algunas ideas básicas sobre teatro de sombras.}

El teatro de sombras es un recurso extraordinariamente interesante para trabajar la capacidad expresiva de nuestro alumnado, además de otros contenidos propios de la psicomotricidad y el currículum oficial de educación infantil (esquema corporal, percepción y estructuración espacio-temporal, expresión verbal y plástica,...).

Sus características básicas son muy simples... uno o más focos de luz y la realización de sombras con el propio cuerpo y/u otros materiales sobre un superficie opaca... bien una pared, el suelo o una sábana colgada de algún punto elevado. A partir de aquí admite múltiples variedades: utilizar sólo el cuerpo o algún segmento corporal (manos, brazos, pies...); utilizar materiales; modificar focos de luz con proyecciones de colores, fotografías, diapositivas, vídeos, luces alternas, etc.

Desde nuestro punto de vista, su utilización en situaciones educativas tiene tres grandes ventajas: 1-requiere muy pocos recursos materiales, por lo que es fácil de utilizar en cualquier contexto y circunstancia; 2-suele motivar mucho al alumnado y genera menos problemas de inhibición que muchas propuestas de expresión corporal; 3-admite una enorme diversidad de posibilidades a la hora de trabajarse, así como de niveles de dificultad, por lo que puede adaptarse a cualquier etapa y contexto educativo.

Las técnicas básicas que trabajamos con nuestro alumnado en las primeras fases son cuatro: 1-el tamaño de la sombra en función de la distancia respecto al foco y el telón; 2-el grosor de la sombra según la colocación frontal o de perfil; 2-mirar siempre al telón mientras se representa, para ver el efecto y poder ajustarlo; 4- no superponer las sombras de diferentes personas, salvo que sea para buscar un efecto concreto que así lo requiera.

Se trata de un recurso didáctico sobre el que no existe demasiada bibliografía. En un artículo muy reciente y completo, López y Canales (2007) revisan las posibilidades del teatro de sombras en Educación Física y aportan numerosas ideas y recursos para su trabajo en EF. En el grupo de trabajo llevamos muchos años trabajando con el teatro de sombras como recursos expresivo en primaria y secundaria; en Barba (2002), De Diego, Subtil y Marugán (2004), Iglesias, López et al (2004) pueden encontrarse algunas de estas experiencias, en las que se explica 
el proyecto desarrollado, el contexto en que se lleva a cabo, las dificultades encontradas y, en varias de ellas, las sesiones completas y los instrumentos de evaluación utilizados, así como una valoración final sobre los resultados obtenidos. Nosotros lo aprendimos de los compañeros de Huesca (Gracia y Tomeo, 1999, 2006) y de alguna lectura posterior (Godall, 1998). En Gracia y Tomeo (1999) puede encontrarse una introducción al teatro de sombras, avalada por muchos años de práctica y experiencia en escuelas unitarias y completas de la provincia de Huesca. En este trabajo explican las características básicas del teatro de sombras, las posibilidades metodológicas y algunas ideas para su puesta en práctica en EF. Godall (1998) realiza una interesante introducción genérica a las posibilidades del teatro de sombras como recurso expresivo en el área de EF. Explica los diferentes tipos de sombras con las que se puede experimentar (el sol y el suelo, un foco y la pared, un foco y un telón o sábana) y aporta ideas concretas sobre actividades que pueden realizarse.

A partir de ese aprendizaje inicial ha sido, sobre todo, un proceso colectivo de investigación-acción (planificar, ponerlo en práctica, observar que tal sale, corregir, volver a poner en práctica...) (Kemmis y McTaggart, 1988; Latorre, 2003; López et al, 2005). Debido a ello teníamos ciertas dudas sobre si los niños de infantil serían capaces de entender las cuestiones más básicas de está interesante herramienta didáctica y lograrían representar una historia sencilla y conocida ante un público predispuesto. El reto merecía la pena y nos lanzamos a él.

3. Método y materiales de la experiencia. Proyecto de aprendizaje sobre «Teatro de Sombras en Educación Infantil».

Los principales objetivos del proyecto eran los siguientes:

- Iniciar al alumnado de educación infantil en el mundo del teatro de sombras, de modo que les genere una experiencia expresiva y vital positiva a la vez que van aprendiendo las técnicas básicas de este recurso.

- Realizar con el alumnado de infantil un proyecto novedoso de cara a la preparación del festival de navidad.

- Comprobar la posibilidad, la viabilidad y la conveniencia de utilizar el teatro de sombras en Educación Infantil.

Por tanto, los contenidos más relevantes son:

- Iniciación a las técnicas básicas del teatro de sombras y la experiencia motriz y expresiva que supone.

- Dramatización de cuentos tradicionales.

La metodología por proyectos se basa en la elaboración de un plan de trabajo que llevar a cabo durante un tiempo y que implica el logro de unos objetivos y la elaboración de un producto final. En este caso, era la representación en el festival de navidad del colegio. El proyecto se comparte con el alumnado desde el principio, por lo que en todo momento los niños saben el sentido que tienen las diferentes actividades de aprendizaje que se llevan a cabo. En muchos casos el alumnado también participa en la planificación, organización y evaluación del proyecto.

El desarrollo del proyecto llevó varias semanas lectivas. Por la organización del horario semanal en educación infantil, sólo disponíamos de una hora por grupo para la clase de psicomotricidad, así que el avance era más lento de lo deseado. Tras comprobar la viabilidad del proyecto en las primeras sesiones de trabajo, se planteó a las maestras tutoras de los tres grupos de infantil la idea de hacer una dramatización de cuentos infantiles mediante teatro de sombras con los grupos de 4 y 5 años y un cuento dramatizado, con diapositivas de fondo, con los de 3 años.

Durante las semanas previas se trabajó con los niños los efectos que su cuerpo y la luz generan sobre el telón, y cómo los materiales pueden ayudar a modificar dichas sombras. Luego hubo que aprender el cuento, repartir los personajes, preparar los materiales necesarios para lograr la sombra requerida, ensayarlo, corregir, pensar con ellos las mejores soluciones... La última semana, los ensayos generales, tal y como luego se iba a hacer en la representación (luces, música, disfraces, etc.). Esta semana fue más intensa, dedicando mucho más tiempo a preparar las

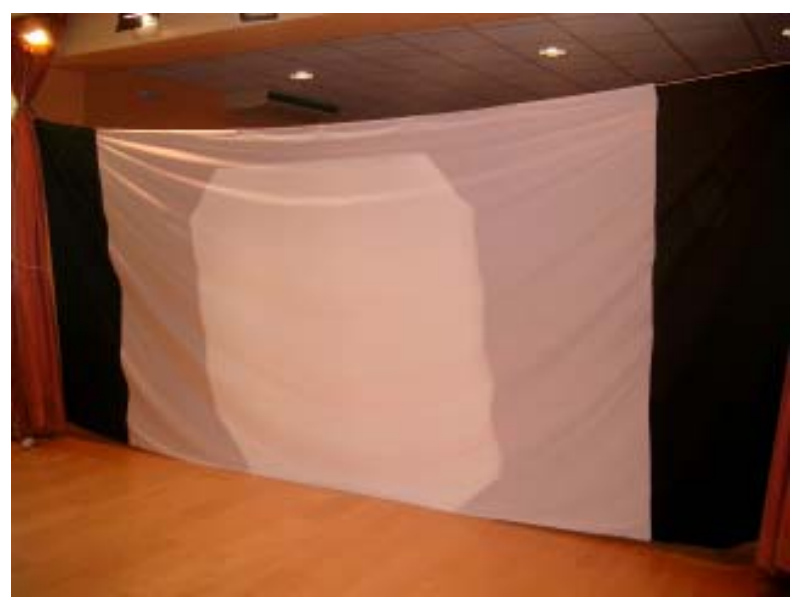

Foto 1. Telón para el teatro de sombras, formado por tela blanca donde se proyectan las sombras y tela negra donde se colocan los niños cuando no quieren que se vea su sombra.

representaciones para el festival, utilizando las horas de las maestrastutoras.

Los Recursos utilizados fueron los siguientes:

-Focos de luz. Es lo más sencillo en un colegio, porque valen muchas cosas: un proyector de diapositivas o de trasparencias, un flexo, una bombilla....

- Un telón ya preparado para el teatro de sombras, compuesto de una sábana blanca en el centro, cosida a dos telas negras en los lados, para facilitar la entrada y salida de los personajes. Es muy fácil de elaborar; hay que comprar la tela blanca y negra en las tiendas, coserlas, poner corchetes en la parte de arriba y pasar una cuerda... Con eso ya tenemos un telón para muchos, muchos años. Para que sea más fácil de montar, es conveniente que el conserje, si le hay en el centro, o nosotros mismos demos un par de taladros en mitad de las aulas en que vayamos a trabajar, y pongamos unas escarpias donde atar el telón. Más rápido y sencillo es una sábana blanca vieja, que se fija a una viga o al techo con unas chinchetas. Vale igual para trabajar con ella, pero no queda igual de bien y no siempre es fácil de colocar en un aula.

-Objetos y ejemplos de sombras. Los materiales pueden ayudar a crear la forma que buscamos. En el teatro de sombras las cosas nunca son lo que parecen. Por ejemplo, las casas de los cerditos son dos niños sujetando unas cartulinas enrolladas y subidos sobre un «ladrillo»; unas uñas de juguete crean la sombra de un dedo largo y afilado; un cartón o una tapa de la caja donde los niños y niñas guardan sus pegamentos, se convierte en espejito mágico; una diadema con cartones pegados puede ser las sombras de las orejas de los cerditos... o las del lobo... depende de la forma del cartón.

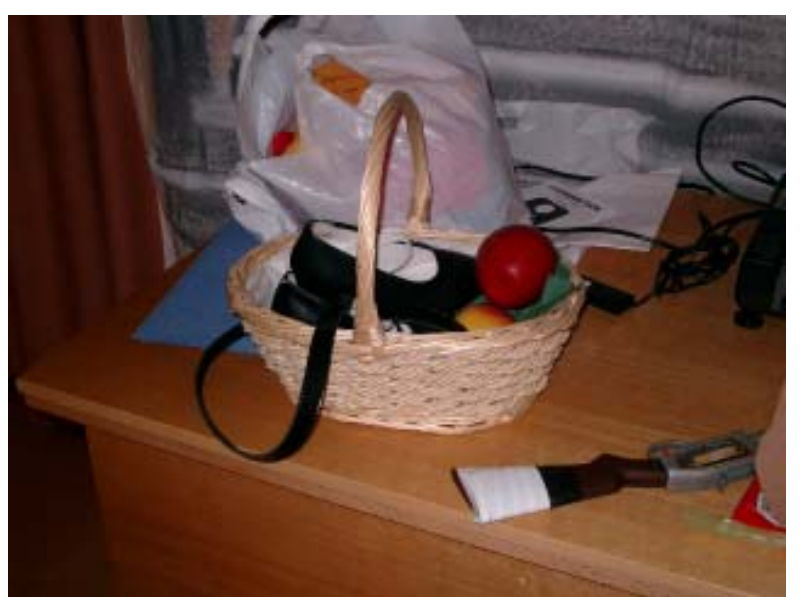

Foto 2. Algunos materiales utilizados (cesta para llevar las manzanas de la madrastra, la escopeta que «identifica en la sombra al cazador...). 


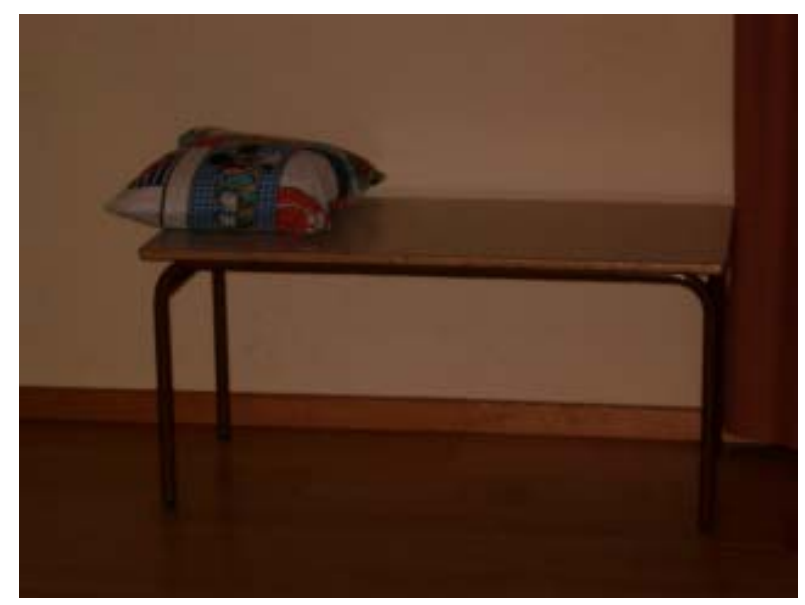

Foto 3. Una mesa con un cojín de los niños, simulará en la sombra la caja de cristal donde los enanitos tumbarán a

Blancanieves tras haber mordido la manzana envenenada.

En las fotos que acompañan el texto pueden verse algunos ejemplos concretos de cómo la utilización de materiales y la posición del cuerpo ayudan a generar las sombras que se buscan para la representación de la historia.

-Dramatización sobre diapositivas con las páginas del cuento. Se hizo con un portátil y un cañón de video. Previamente digitalizando las páginas del cuento, retocándolas o variándolas en función de la modificación que se hizo del cuento para adaptarlo a la clase de tres años de este colegio. Sobre dichas imágenes actúan los niños, de manera que se asegura que ellos no se pierdan y el público pueda seguir mejor la historia.

4. Resultados de la experiencia. El desarrollo de las representaciones en el festival de navidad.

El día del festival comenzamos a trabajar pronto. Lo primero fue preparar la sala y los materiales antes de que comenzaran a llegar las familias, el alumnado y el profesorado de la escuela. Diez minutos antes de comenzar la función llegaron los niños y los de Infantil se sentaron en las primeras filas. Ya estaba todo a punto. El director pidió silencio, deseó felices fiestas y presentó la función. El alumnado de Infantil comenzaba la función. Primero salió el grupo de 5 años, a representar el cuento de Blancanieves. Se apagaron las luces y sonó una melodía de Mozart. Se encendieron los proyectores y comenzó la magia del teatro de sombras. Luz, sombras y siluetas. Una voz narraba la historia... y los niños la representaban:

«La reina con su espejo, Blancanieves, el cazador (foto 6), el bosque, la casa con las camas pequeñas, los enanitos (foto 7), la man-

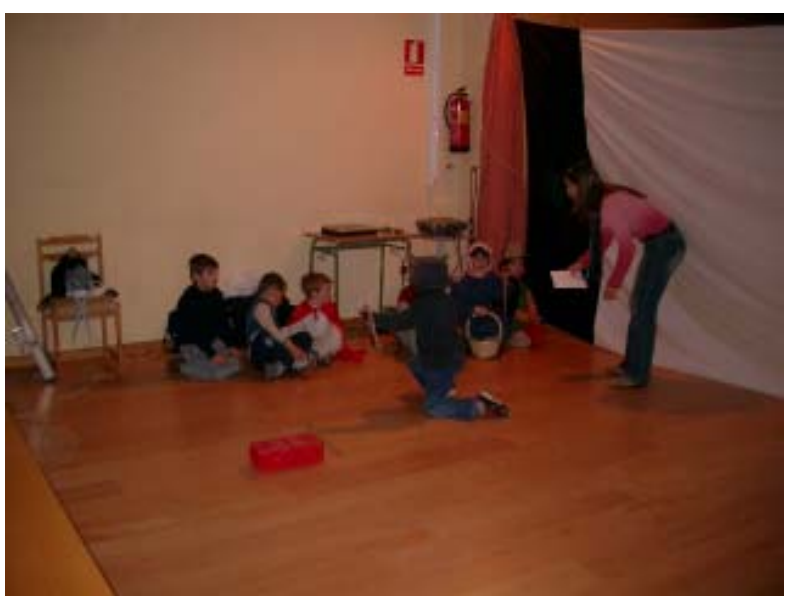

Foto 4. Últimos consejos antes de empezar.

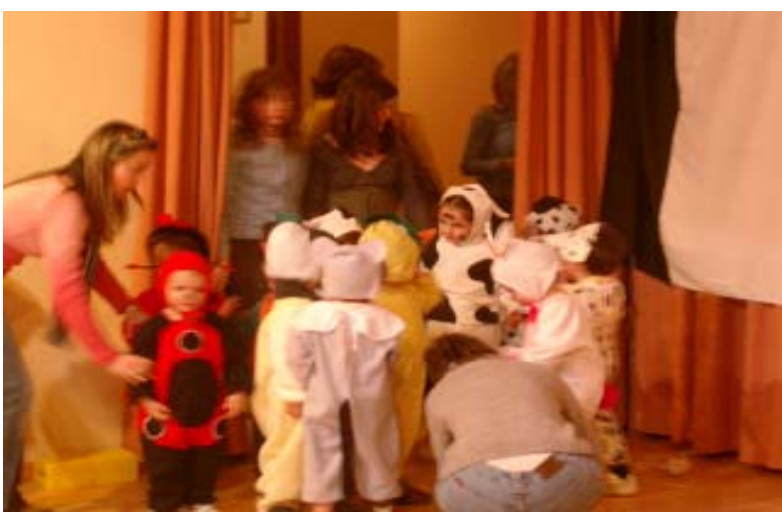

Foto 5. Colocando a los más pequeños en sus puestos para empezar la representación.

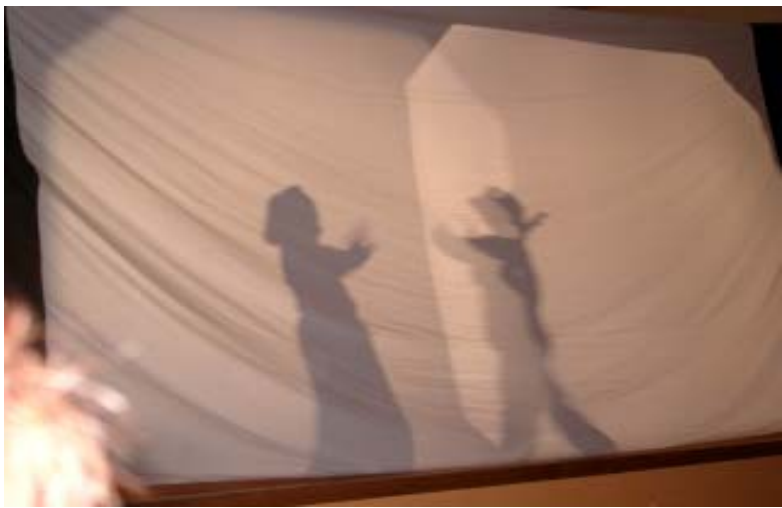

Foto 6. El cazador se despide la Blancanieves antes de dejarla huir en el bosque.

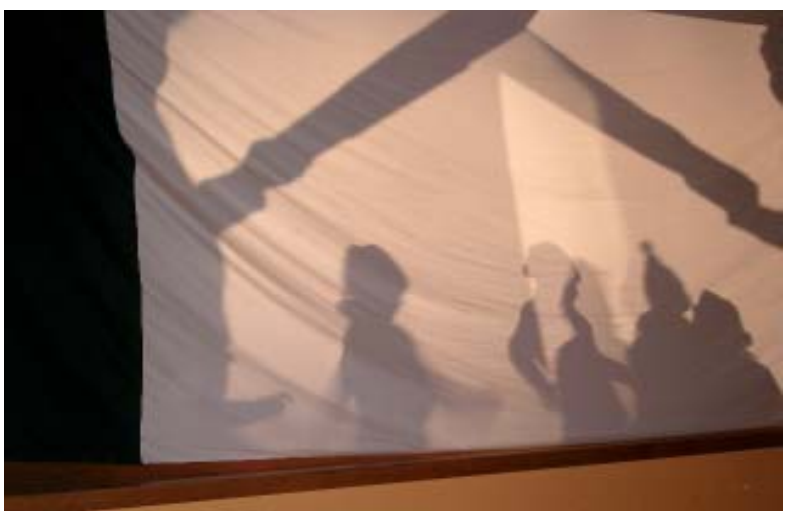

Foto 7. Llegan los enanitos a su casa y encuentran a Blancanieves.

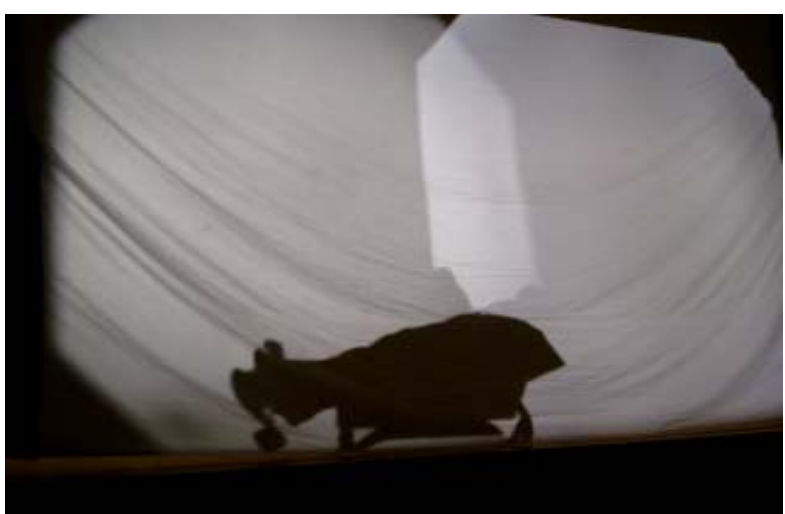

Foto 8. Blancanieves acaba de ser colocada en su cajita de cristal tras haber mordido la manzana envenenada. 


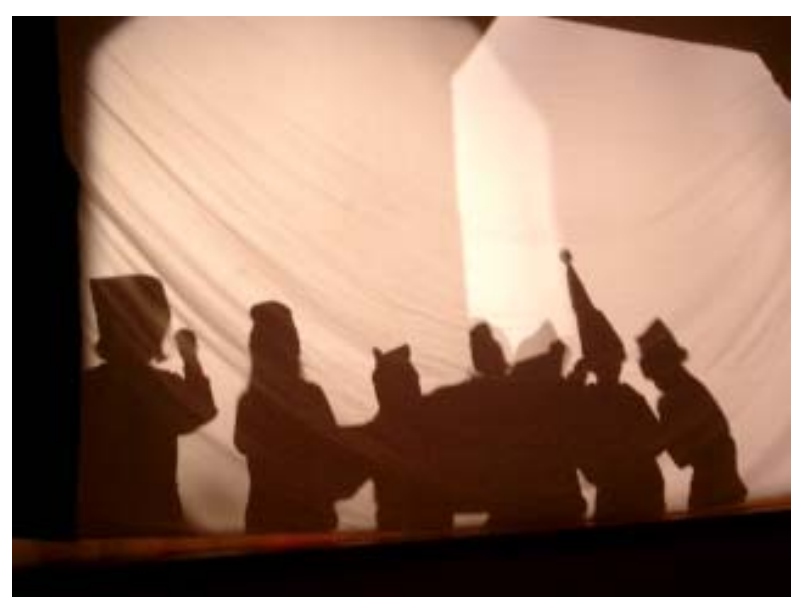

Foto 9. Los enanitos lloran desconsolados ante la caja de cristal de Blancanieves.

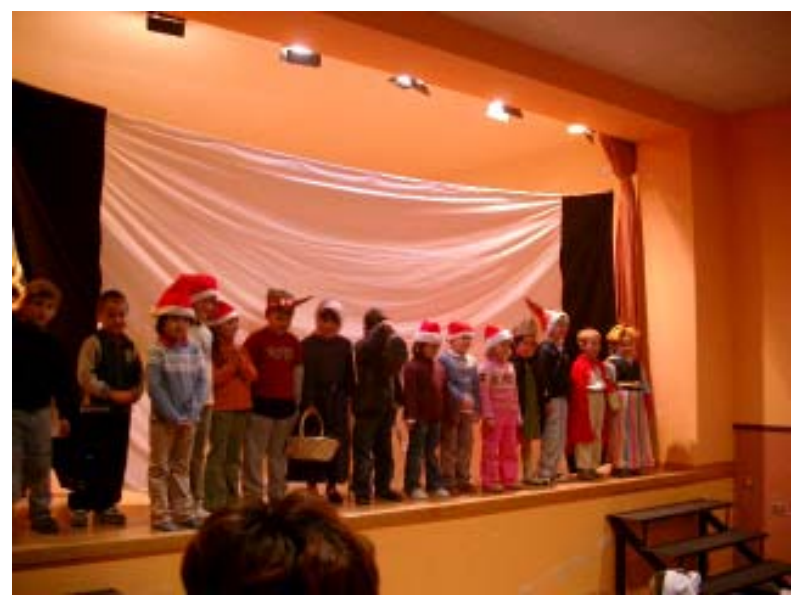

Foto 10. Los artistas saludan a su público al terminar.

zana, el sueño (foto 8), el llanto de los enanitos (foto 9), el principiey su caballo, el beso, el despertar, la alegría...».

Resonaron los aplausos de niños, familiares y compañeros. Salieron los niños actores a saludar y a recibir el reconocimiento de compañeros y padres (foto 10). Luego bajaron a sentarse en sus butacas, ahora ya como espectadores.

A continuación les tocaba el turno a los de 4 años, dramatizando la historia de «Los tres cerditos y el lobo». Suben desde las butacas, con el proyector apagado y tras bambalinas la maestra de apoyo ajusta los disfraces, las diademas, las orejas, las colas,... «construyen» la casa. Cuando ya quedó todo preparado, apagan las luces. Se vuelve a escu-

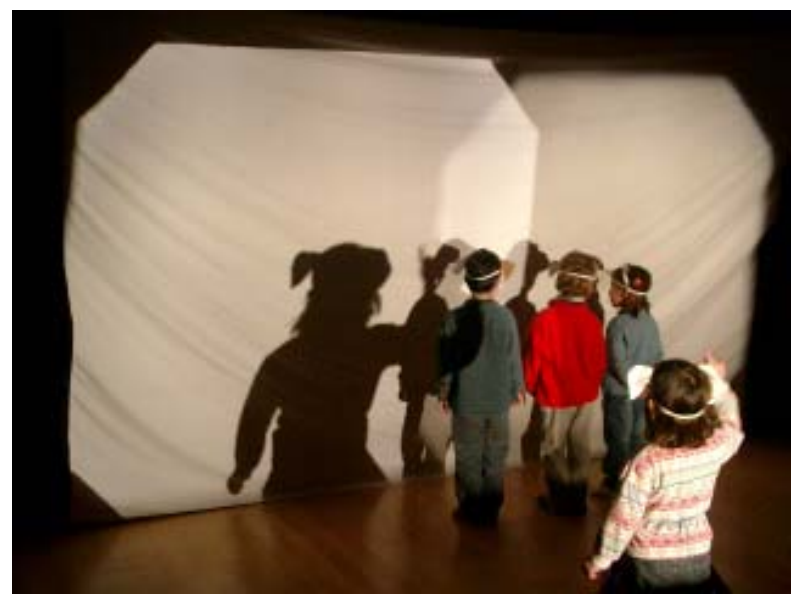

Foto 11. La mamá de los tres cerditos da los últimos consejos a sus hijos antes de su marcha.

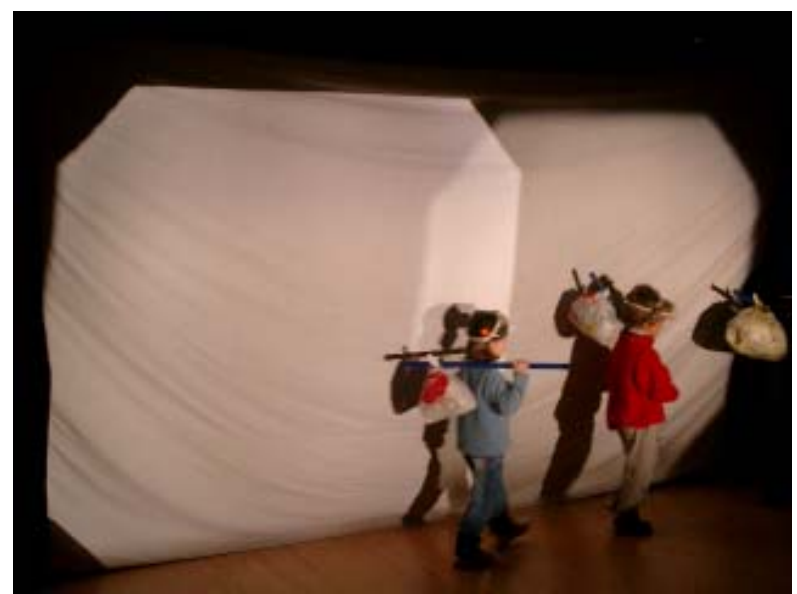

Foto 12. Los tres cerditos cogen sus atillos y deciden irse a recorrer mundo.

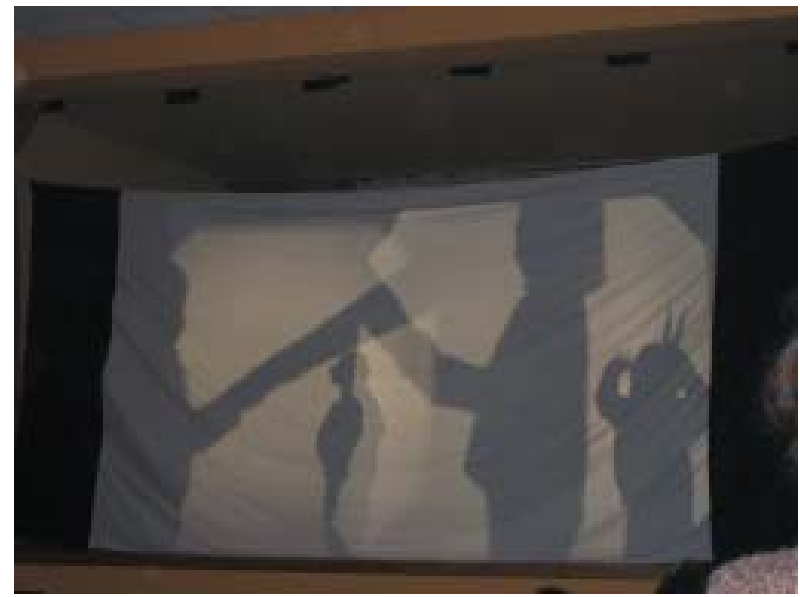

Foto 13. El cerdito dentro de la casa de paja y el lobo soplando para intentar tirarla.

charse de fondo otra melodía de Mozart, se encienden los proyectores. Acción. La voz de la narradora vuelve a escucharse clara:

«Los cerditos en la granja con su mamá (foto 11)... deciden irse a conocer mundo (foto 12)... las tres casas: paja, madera, piedra. El lobo llamando a la de paja,... no le abren... - -soplaré y soplare y la casa derribaré»-(foto 13),... y en efecto, la casa se cae. Carreras. La casa de madera se levanta; los dos cerditos están dentro: - «Abridme cerditos, $O$ soplaréy soplarey la casa derribaré»-. (foto 14) No le abren, sopla una vez, dos veces ... y la casa se cae.... carreras ... se levanta la casa de piedra. Tres cerditos dentro (foto 15). El lobo sopla y sopla, pero la casa no se menea. El lobo trepa hasta la chimenea, mientras los cerditos ponen una

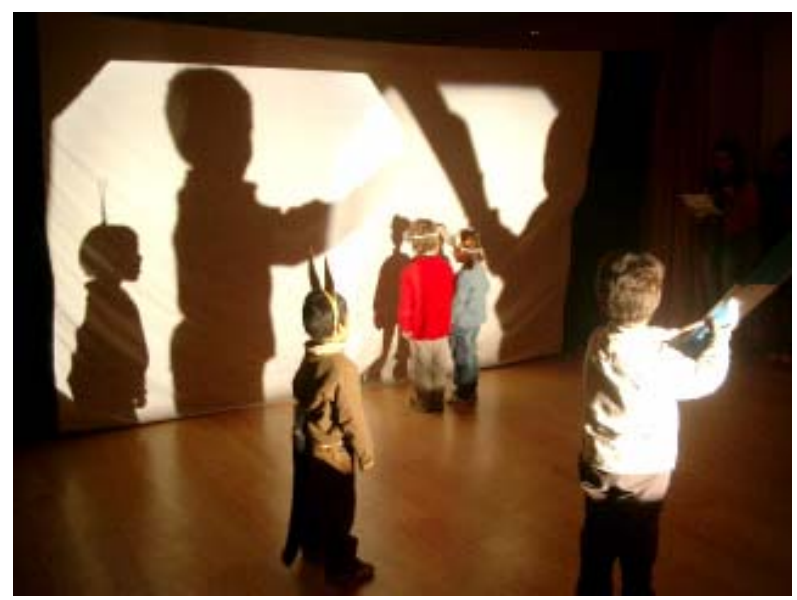

Foto 14. Llega el lobo a la casa del segundo cerdito decidido a comerse a dos de los hermanos. 


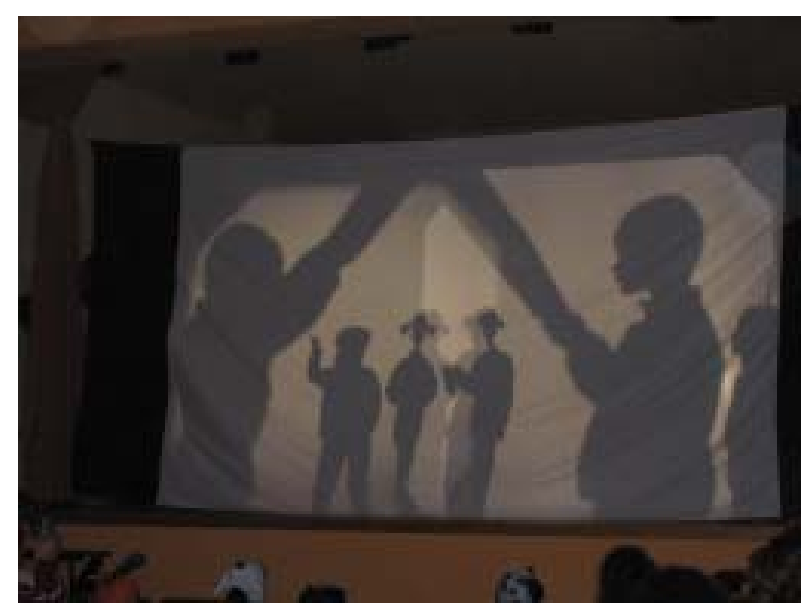

Foto 15. Los tres cerditos dentro de la casa (formada por dos alumnos que, subidos en ladrillos de psicomotricidad, sujetan unas cartulinas enrolladas). Fuera de la misma, a la derecha de la fotografía, puede verse al lobo esperando.

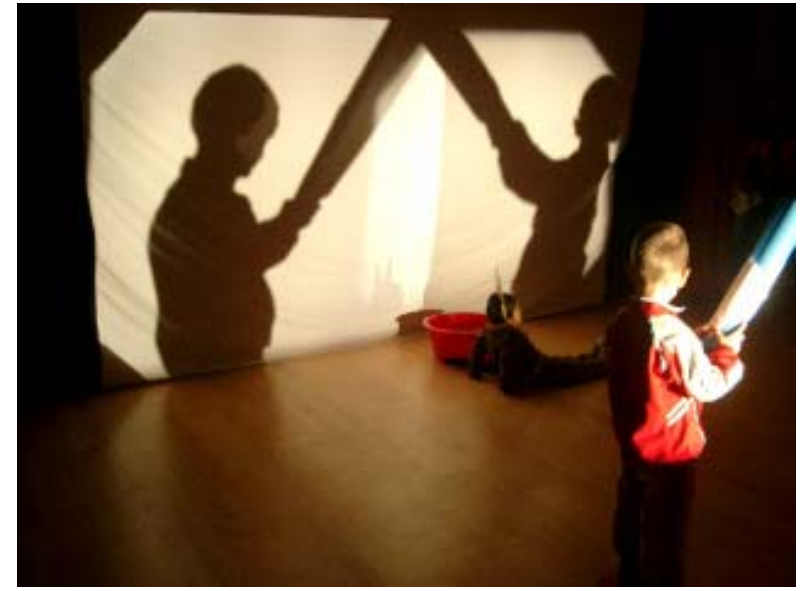

Foto 16. El lobo cae en el caldero simulado en la sombra con un gran barreño.

olla al fuego. El lobo cae en la olla (foto 16), aúlla de dolor y sale corriendo; tres cerditos bailando...».

Se apagan los focos, se encienden las luces.... aplausos, aplausos. Los niños de 4 años también recibieron su ración de aplausos, el reconocimiento por su representación.

En tercer lugar actuó el grupo de 3 años, con el cuento de «El secreto» (Battut, 2005). Narra la historia de una ratoncilla que se en-

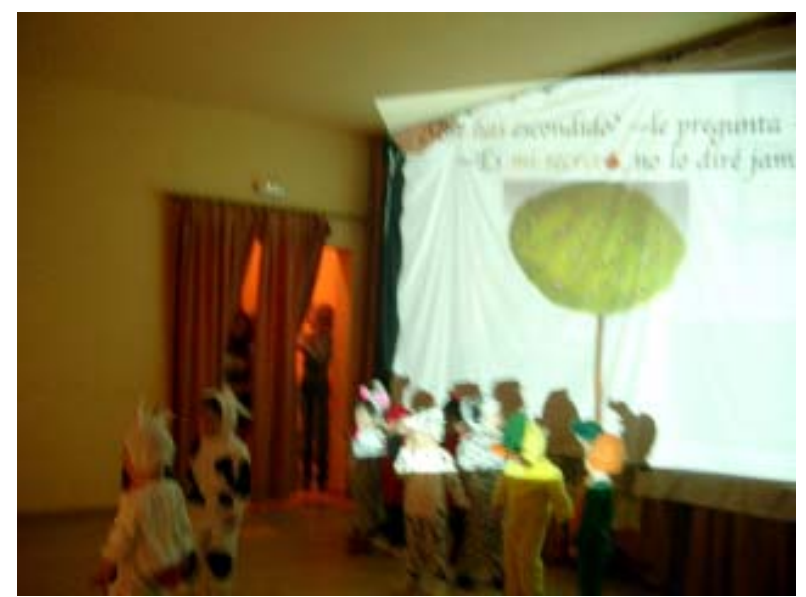

Foto 17: Los más pequeños, actúan delante del telón de sombras, sobre el que se va proyectando la historia que representas con power point. cuentra una manzana y decide convertirla en su secreto, así que la entierra, para que nadie lo sepa. Un tiempo después se convierte en un árbol que da sus frutos, mientras los animales siguen preguntando a la ratoncilla por su secreto escondido (foto 17).

Los niños de tres años no hacen teatro de sombras, sino dramatización sobre diapositivas. En parte porque era mucho más viable dada su edad, y en parte porque se pretendió introducir cierta variedad en el festival y no limitar la actuación del alumnado de Infantil a realizar tres actuaciones seguidas de teatro de sombras.

Tras laúltima actuación se cerró el telón. Había que desmontar todo rápidamente, para que pudieran comenzar las actuaciones de los grupos de Primaria. En los camerinos se recogió y organizó todo, mientras los niños de primero comenzaban su villancico en inglés. Al salir se recibieron felicitaciones de algunas madres y compañeros. El proyecto había llegado a su fin y, afortunadamente, había salido bien.

\section{Valoración final sobre la experiencia.}

El desarrollo del proyecto ha superado con creces nuestras expectativas respecto a las posibilidades del alumnado de Infantil. Teníamos ciertas dudas sobre su aplicación didáctica en este ciclo, pero nos han sorprendido gratamente. Hemos comprobado que el alumnado de 4 y 5 años es perfectamente capaz de captar las ideas fundamentales de esta técnica: la importancia de la colocación de las personas y objetos en un espacio delimitado para representar lo que se pretende.

La experiencia ha reforzado nuestras convicciones sobre las posibilidades pedagógicas del teatro de sombras, tanto desde lo referente a la expresión corporal, hasta la integración y participación del alumnado. Ha sido un recurso muy eficaz a la hora de integrar en el grupo a cierto sector del alumnado que habitualmente suele permanecer aislado y/o excluido una parte importante de la jornada escolar. Por ejemplo, los niños inmigrantes que no comprenden muy bien el idioma, los niños menos hábiles motriz, afectiva o socialmente. Hemos vuelto a comprobar cómo este tipo de trabajo permite que se sienten muy cómodos, que vayan superando los procesos de aislamiento, exclusión e inhibición, que den salida a su capacidad creativa y a su capacidad de relación y cooperación.

Es perfectamente aplicable a cualquier contexto. Los recursos materiales son mínimos y están al alcance de todos. Se trata de una estrategia lo suficientemente flexible y abierta como para poder adaptarse a todo tipo de edades, grupos y centros. Los ingredientes son sencillos: un foco de luz, un trozo de tela blanca, una pizca de imaginación y un buen chorro de ganas de trabajar. Se mezcla bien y se remueve, dando tiempo a que hierva y... el guiso suele salir sabroso e interesante en la inmensa mayoría de las ocasiones.

El teatro de sombras es un recurso extraordinariamente interesante para trabajar la capacidad expresiva de nuestro alumnado, además de otros contenidos propios de la psicomotricidad y el currículum oficial de educación infantil. Tiene muchísimas posibilidades, tanto de contenidos como en complejidad de los montajes y representaciones. El proyecto puede evolucionar y adaptarse hasta abarcar muchas de las temáticas que nos propone el currículum oficial de las diferentes etapas educativas (esquema corporal, orientación y estructuración espacial y temporal, música, plástica, leguaje verbal, idiomas, conocimiento del medio...).

Nuestra valoración de la experiencia ha sido positiva. La representación final, el colofón del proyecto, ha salido bien. Las valoraciones de madres y profesorado también han sido muy positivas. Alguno añadió que ya era de hora de hacer algo distinto a los villancicos de todos los años. Una valoración más específica hace referencia a la técnica utilizada en la última representación, la de los tres años, porque ha sido una buena combinación entre las dos técnicas de dramatización.

En cuanto a los inconvenientes, hay que reconocer que se trata de proyectos que generan bastante trabajo, de forma que pueden ser un tanto duro si se hacen en soledad, como ocurrió en este caso, pero en cambio mucho más viables, agradables y fructíferos cuando hay varias manos «tirando del carro». 
Como propuestas de mejora para próximas ocasiones, o para otros compañeros interesados en la temática, creemos que es fundamental trabajarlo de forma conjunta con las maestras tutoras de los grupos de infantil, de modo que sea un trabajo más globalizado y no exclusivo del programa y la especialista de «psicomotricidad». En caso de disponer de más tiempo para su preparación, creemos que sería interesante implicar más al alumnado en la elección del cuento y la preparación de las diferentes escenas y detalles para la representación.

\section{Conclusiones.}

Los objetivos iniciales del proyecto se han cumplido satisfactoriamente. El alumnado de educación infantil se ha iniciado en el mundo del teatro de sombras, han adquirido un buen dominio de las técnicas básicas de este recurso y han tenido una experiencia expresiva y vital positiva, en la que todo el alumnado ha tenido un papel que representar, una labor importante que realizar para alcanzar un objetivo común.

Las representaciones en el festival de navidad han salido muy bien. Las valoraciones han sido positivas por parte de todo el mundo (niños, madres, compañeras); en parte por la novedad que ha supuesto, en parte por la vistosidad del propio recurso y en parte por lo bien que ha salido todo el proyecto.

Hemos comprobado la posibilidad, la viabilidad y conveniencia de utilizar el teatro de sombras en Educación Infantil. Tras la experiencia acumulada en primaria teníamos ciertas dudas sobre su utilización en Infantil, que han sido despejadas tras la realización de este proyecto. En el anterior apartado se comentan las múltiples posibilidades didácticas que tiene este recurso, así como lo fácil y barato que resulta.

Un aspecto importante del proyecto, es la integración de todo el alumnado en el mismo desde el principio. Este tipo de procesos educativos, con un fin claro y conocido, y donde todo el alumnado tiene un papel importante a cumplir de cara al éxito colectivo, es un reforzador poderoso de cara a lograr una mayor motivación e implicación del alumnado en los procesos de enseñanza-aprendizaje que llevamos a cabo en los centros educativos.

Por último, como propuesta de mejora, consideramos que es importante desarrollar este tipo de proyectos desde un planteamiento más global, de forma conjunta con las maestras tutoras de los correspondientes grupos de infantil.

\section{Agradecimientos.}

Para llevar a cabo este trabajo, conté con la ayuda de varios compañeros del colegio, a quienes estoy muy agradecida, tanto como a un compañero del grupo de trabajo del que formo parte y al secretario, que me echaron una mano con los preparativos de última hora, como a mi compañera de Educación Física, que me ayudó con las TIC y la presentación de imágenes y textos de fondos que utilicé con los niños de tres años.

\section{Referencias.}

Barba Martín, JJ. (2002) Teatro de sombras en la Escuela Rural. Revista Pastopas,1 (27-32).

Battut, E. (2005) «El secreto». Madrid: Kókinos. (Traducción de Esther Rubio).

De Diego, E.; Subtil, P. y Marugán, L. (2004) «Taller de sombras corporales». En Actas del IV Congreso Estatal y II Iberoamericano de Actividades Físicas Cooperativas. Valladolid: La Peonza. (CD$\mathrm{R})$.

Gracia, F y Tomeo, M (1999) Experiencias del seminario del CPR de Sabiñànigo: Encuentros, Sombras chinas y danzas de Paloteo» En: López, VM. (Coord.) «La Educación Física en la Escuela Rural» Segovia: Pastopas-Librería Diagonal (97-120).

Gracia, F y Tomeo, M (2006) Experiencias del seminario del CPR de Sabiñànigo: Encuentros, Sombras chinas y danzas de Paloteo» En:
López, VM. (Coord.) «La Educación Física en la Escuela Rural». Buenos Aires: Miño y Dávila. (Reedición ampliada) (89-111).

Godall, T. (1988) La sombra corporal. El reconocimiento de la propia expresión en el espacio y en uno mismo. Publicaciones de la EUM de Melilla, 28 (777-786). Melilla: Universidad de Granada.

Kemmis, S y McTaggart (1988) Como planificar la InvestigaciónAcción. Barcelona: Laertes.

Latorre, A. (2003). La investigación-acción. Barcelona: Graó.

López, V.M. (coord.) y otros (2005) Doce años de Investigación-Acción en Educación Física. La importancia de las dinámicas colaborativas en la formación permanente del profesorado. El caso del grupo de trabajo internivelar de Segovia. Lecturas de Educación Física y Deportes, 90. (www.efdeportes.com; consultado 2-3-06).

Iglesias, P.; López, VM. Etal. (2004) «Unidad didáctica interdisciplinar: teatro de sombras e interculturalidad. Intentando avanzar hacía la integración del alumnado inmigrante en el área de Educación Física». En Pérez, D.; López, VM.; Iglesias, P. (coord.) La Atención a la diversidad en Educación Física. Sevilla: Wanceulen (158-189).

López Villar, C. y Canales Lacruz, I. (2007) El teatro de sombras en Educación Física. Tandem, 23(113-120). 